\title{
Fertilizante mineral e resíduo orgânico sobre características agronômicas da soja e nutrientes no solo ${ }^{1}$
}

\author{
Mineral fertilizer and organic waste on soybean crop and soil nutrients
}

\author{
Everson Reis Carvalho ${ }^{2 *}$, Pedro Milanez de Rezende ${ }^{3}$, Messias José Bastos de Andrade ${ }^{4}$, Alexandre Martins \\ Abdão dos $\operatorname{Passos}^{5}$ e João Almir Oliveira ${ }^{6}$
}

\begin{abstract}
Resumo - Objetivou-se avaliar o efeito do fertilizante mineral NPK associado ao resíduo orgânico "cama de frango", sobre as características agronômicas da soja bem como os teores de nutrientes em um Cambissolo. O experimento foi conduzido no município de Itutinga, sul de Minas Gerais, no delineamento em blocos casualizados, com três repetições em esquema de parcela subdividida. A cultivar utilizada no experimento foi a BRS Favorita RR. Os tratamentos aplicados às parcelas foram constituídos por quatro doses de "cama de frango" $\left(0 ; 3 ; 6 \mathrm{e} 9 \mathrm{Mg} \mathrm{ha}^{-1}\right)$, aplicados em área total. As subparcelas constituíram as cinco doses do fertilizante mineral formulado NPK 04-30-10 (0;100; 200; 300 e $\left.400 \mathrm{~kg} \mathrm{ha}^{-1}\right)$, aplicados ao sulco de semeadura. A adubação com o fertilizante mineral proporciona aumento na altura de planta e de inserção do primeiro legume, número de legumes por planta e na produtividade de grãos da cultura da soja. A adubação com o resíduo orgânico "cama de frango" eleva a altura de planta e de inserção do primeiro legume, massa de 100 grãos, número de legumes por planta e o rendimento de grãos de soja, porém em doses mais elevadas favorece o acamamento das plantas. A utilização da cama de frango é viável em termos agronômicos e econômicos na cultura da soja. A adição de cama de frango eleva os teores de potássio e enxofre no solo.
\end{abstract}

Palavras-chave - Adubação mineral. Adubação orgânica. Cama de frango. Glycine max.

\begin{abstract}
The objective of this study was to evaluate the effect of mineral fertilizer NPK associated with the organic waste "poultry litter" on the agronomic characteristics of soybean as well as nutrient levels in the Cambisol. The experiment was carried out in Itutinga, southern Minas Gerais state, Brazil, in a randomized blocks experimental design with three replications in split-plot. The cultivar used was BRS Favorita RR. The treatments applied to plots consisted on four doses of "poultry litter" $\left(0 ; 3 ; 6\right.$ and $\left.9 \mathrm{Mg} \mathrm{ha}^{-1}\right)$, applied in the total area. The subplots were the five doses of mineral fertilizer NPK 04-30-10 (0; 100; 200; 300 and $400 \mathrm{~kg} \mathrm{ha}^{-1}$ ), applied to the groove seeding. Fertilization with mineral fertilizers provides an increase in plant and first pod height, number of pods per plant and yield of soybean. Fertilization with organic waste "poultry litter" increases the plant and first pod height, weight of 100 grains, number of pods per plant and yield of soybean, however at higher doses favors the lodging of plants. The use of poultry litter is viable in agronomic and economic terms in the soybean crop. The addition of poultry litter increases the contents of potassium and sulfur in the soil.
\end{abstract}

Key words - Mineral fertilizer. Organic fertilizer. Poultry litter. Glycine Max.

\footnotetext{
*Autor para correspondência

${ }^{1}$ Recebido para publicação em 13/08/2010; aprovado em 10/05/2011

Parte da Dissertação de Mestrado do primeiro autor, apresentada ao Curso de Pós-Graduação em Agronomia/Fitotecnia/Universidade Federal de Lavras/UFLA

${ }^{2}$ Departamento de Agricultura/Universidade Federal de Lavras/UFLA, Caixa Postal 3037, Lavras-MG, Brasil, 37.200-000, eversonreiscarvalho@ hotmail.com

${ }^{3}$ Departamento de Agricultura/UFLA, Lavras-MG, Brasil, pmrezend@dag.ufla.br

${ }^{4}$ Departamento de Agricultura/UFLA, Lavras-MG, Brasil, mandrade@dag.ufla.br

${ }^{5}$ Pesquisador EMBRAPA Rondônia, Brasil, abdao@cpafro.embrapa.br

${ }^{6}$ Departamento de Agricultura/UFLA, Lavras-MG, Brasil, jalmir@dag.ufla.br
} 


\section{Introdução}

A produção de soja [Glycine $\max ($ L.) Merrill] no país é muitas vezes limitada pelos altos custos de produção e, entre os insumos, o fertilizante é o mais oneroso, com participação da ordem de 23 a $27 \%$ no custo total de produção, variando a cada safra (CASTRO;REIS; LIMA, 2006; MENEGATTI; BARROS, 2007).

O Brasil importa grande parte dos fertilizantes minerais. Visando diminuir essa dependência e otimizar a utilização de fertilizantes, o país deve atentar para alternativas de fertilização dos solos, em muitas regiões existe a possibilidade de aproveitamento de resíduos, os quais constituem opção interessante, quando bem utilizados. $\mathrm{O}$ uso de estercos animais pode favorecer a infiltração e a absorção da água e aumentar a capacidade de troca de cátions dos solos (HOFFMANN et al., 2001). Entre outros atributos, ressalta-se a redução na capacidade máxima de adsorção de P (SOUZA et al., 2006).

Andreola et al. (2000), estudando adubações orgânica e mineral, observaram que o uso de esterco de aves proporcionou acúmulo de $\mathrm{K}$, o que corrobora com Moreti et al. (2007), que constataram que esterco de galinha e esterco de galinha + metade da adubação mineral foram os que mais contribuíram para a melhoria dos atributos químicos do solo. Dentre vários resíduos testados para a cultura da soja, Lemainski e Silva (2006), concluíram que o aproveitamento do biossólido líquido (resíduo do tratamento de esgotos) como fertilizante é viável. Corrêa et al. (2008), por sua vez, concluíram que a produtividade da soja é favorecida pela aplicação de lodo de esgoto centrifugado e de biodigestor, escória de aciaria (resíduo da indústria da fundição do aço e do ferro-gusa) e lama cal (resíduo da fabricação de papel e celulose). Bhattacharyya et al. (2008) relataram que as culturas da soja e do trigo, cultivadas em sucessão, responderam à aplicação de NPK minerais, mas o rendimento máximo foi obtido com o NPK + esterco bovino, demonstrando a importância da matéria orgânica. Os autores observaram ainda que os rendimentos diminuíram com o tempo nas parcelas sem adubação e nos tratamentos com apenas fertilizantes minerais, ao passo que nos tratamentos onde foi utilizado o esterco foram observados incrementos, ainda relataram que a eficiência agronômica dos fertilizantes foram maiores nas parcelas que receberam adubo mineral mais o resíduo orgânico. Ghosh et al. (2009), trabalhando com consórcio soja-sorgo sob seis combinações de adubação orgânica e mineral, observaram que a aplicação de $75 \%$ NPK mineral recomendado + esterco de galinha ou esterco bovino ou fósforo composto é uma opção viável de gestão de nutrientes para atender a demanda.

Na agricultura brasileira, o uso de adubos orgânicos como cama de aves, tem se tornado alternativa interessante, devido ao aumento da oferta (COSTA et al., 2009). Por isso os trabalhos realizados demonstrando a viabilidade da utilização da cama de frango como fertilizante são de suma importância (COSTA et al., 2009; MELLO; VITTI, 2002; MENEZES et al., 2004; RIBEIRO et al., 2009). Esse fato, aliado ao aumento do custo dos fertilizantes minerais e a crescente poluição ambiental, gera aumento na demanda por pesquisas para avaliar a viabilidade técnica e econômica da utilização de resíduos orgânicos (MELO et al., 2008). De acordo com LIU et al. (2009), a combinação de condicionadores orgânicos com fertilizantes minerais é fundamental para desenvolver estratégias de adubações mais sustentáveis.

Objetivou-se com o presente trabalho avaliar a utilização do fertilizante mineral NPK associado ao resíduo orgânico "cama de frango", sobre características agronômicas da soja e nos teores de nutrientes em um Cambissolo do sul de Minas Gerais.

\section{Material e métodos}

O experimento foi conduzido em 2008/09, na Fazenda Milanez localizada em Itutinga - MG, situada a $21^{\circ} 23^{\prime}$ latitude $\mathrm{S}$ e $44^{\circ} 39^{\prime}$ longitude $\mathrm{W}$ de Greenwich, com altitude média de $958 \mathrm{~m}$. A região apresenta inverno seco e verão chuvoso, com as maiores precipitações em dezembro e janeiro, quando a média mensal chega a 254 e $321 \mathrm{~mm}$, respectivamente; a precipitação média anual é de $1.460 \mathrm{~mm}$. Segundo a classificação internacional de Köppen, o clima é do tipo Cwa, temperado chuvoso e mesotérmico, com as maiores temperaturas ocorrendo em dezembro, janeiro e fevereiro, com médias de 22,2; 22,6 e 22, $8^{\circ} \mathrm{C}$, respectivamente (DANTAS; CARVALHO; FERREIRA, 2007).

$\mathrm{O}$ delineamento experimental utilizado foi em blocos casualizados, com três repetições em esquema de parcela subdividida. Os tratamentos aplicados às parcelas foram quatro doses de cama de frango $(0 ; 3$; 6 e $9 \mathrm{Mg} \mathrm{ha}^{-1}$ ) aplicadas em área total no dia anterior à semeadura e incorporadas com gradagem leve. Cada parcela experimental foi constituída de $50 \mathrm{~m}^{2}$. O resíduo orgânico denominado "cama de frango" foi obtido de galpões de avicultura sendo constituído de palha de arroz, excretas, penas e restos de ração, cuja características físicas e químicas estão apresentadas na Tabela 1. Nas subparcelas foram utilizadas cinco doses do fertilizante mineral formulado NPK 04-30-10 $(0 ; 100 ; 200 ; 300 \mathrm{e}$ $400 \mathrm{~kg} \mathrm{ha}^{-1}$ ) com $6,10 \%$ de $\mathrm{Ca}+2,97 \%$ de $\mathrm{S}+0,06 \%$ de $\mathrm{B}+0,97 \%$ de $\mathrm{Mn}+0,31 \%$ de $\mathrm{Zn}$, aplicados manualmente ao sulco de semeadura. A subparcela foi $10 \mathrm{~m}^{2}$, sendo constituída de 4 fileiras de plantas de 5 metros de comprimento, espaçadas em $0,5 \mathrm{~m}$. As duas fileiras externas e $0,5 \mathrm{~m}$ de cada extremidade das fileiras úteis constituíram as bordaduras. 
Tabela 1 - Características físicas e químicas do resíduo orgânico cama de frango, Itutinga, MG

\begin{tabular}{|c|c|c|}
\hline Parâmetro & Unidade & Resultado \\
\hline $\mathrm{pH}$ em água $1 / 2$ & - & 7,4 \\
\hline Condutividade elétrica (CE) $1 / 2$ & $\mathrm{dS} \mathrm{m} \mathrm{m}^{-1}$ & 26,4 \\
\hline Capacidade de retenção de água & $\mathrm{mL} \mathrm{g}^{-1}$ & 2,1 \\
\hline Densidade aparente & $\mathrm{g} \mathrm{cm}^{-3}$ & 0,4 \\
\hline Carbono - total & $\%$ & 41,1 \\
\hline Matéria orgânica (MO) & $\%$ & 82,0 \\
\hline Nitrogênio $(\mathrm{N})$ total & $\%$ & 4,4 \\
\hline N-amônio & $\mathrm{mg} \mathrm{kg}^{-1}$ & 362,0 \\
\hline N-nitrato & $\mathrm{mg} \mathrm{kg}^{-1}$ & 32,0 \\
\hline Fósforo $(\mathrm{P})$ total & $\mathrm{g} \mathrm{kg}^{-1}$ & 8,5 \\
\hline Potássio $(\mathrm{K})$ total & $\mathrm{g} \mathrm{kg}^{-1}$ & 37,0 \\
\hline Sódio $(\mathrm{Na})$ & $\mathrm{g} \mathrm{kg}^{-1}$ & 4,5 \\
\hline Cálcio $(\mathrm{Ca})$ & $\mathrm{g} \mathrm{kg}^{-1}$ & 31,0 \\
\hline Magnésio (Mg) & $\mathrm{g} \mathrm{kg}^{-1}$ & 11,6 \\
\hline Enxofre $(\mathrm{S})$ & $\mathrm{g} \mathrm{kg}^{-1}$ & 6,2 \\
\hline Boro (B) & $\mathrm{mg} \mathrm{kg}^{-1}$ & 46,7 \\
\hline Cobre $(\mathrm{Cu})$ & $\mathrm{mg} \mathrm{kg}^{-1}$ & 119,0 \\
\hline Ferro $(\mathrm{Fe})$ & $\mathrm{mg} \mathrm{kg}^{-1}$ & 2324,0 \\
\hline Manganês (Mn) & $\mathrm{mg} \mathrm{kg}^{-1}$ & 691,0 \\
\hline Zinco (Zn) & $\mathrm{mg} \mathrm{kg}^{-1}$ & 642,0 \\
\hline
\end{tabular}

*Análises realizadas pelo Departamento de Ciência do Solo da Universidade Federal de Lavras

O solo da área experimental foi classificado como Cambissolo (EMBRAPA, 2006), com as seguintes características químicas e físicas, avaliadas de acordo com Ribeiro et al. (1999), na camada de 0,00 - 0,20 m de profundidade, amostrado antes da instalação do experimento: $\mathrm{pH}$ em água de 5,4 (acidez média); 2,0 $\mathrm{mg} \mathrm{dm}^{-3}$ de $\mathrm{P}$ (muito baixo), determinado com extrator Mehlich 1; $98 \mathrm{mg} \mathrm{dm}^{-3}$ de $\mathrm{K}$ (bom); 14,9 $\mathrm{mg} \mathrm{dm}^{-3}$ de S (muito bom), determinado com extrator fosfato monocálcico em ácido

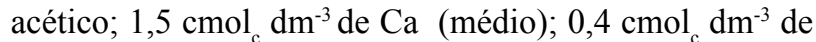
$\mathrm{Mg}$ (baixo); 0,5 $\mathrm{mg} \mathrm{dm}^{-3}$ de Zn (baixo); 32,6 $\mathrm{mg} \mathrm{dm}^{-3} \mathrm{de}$ Fe (bom); 4,8 $\mathrm{mg} \mathrm{dm}^{-3}$ de Mn (baixo); $1,5 \mathrm{mg} \mathrm{dm}^{-3} \mathrm{de} \mathrm{Cu}$

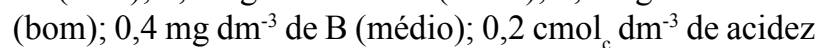

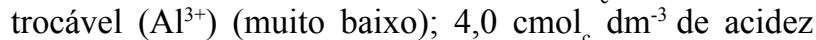
potencial (H+Al) (médio); 2,2 $\mathrm{cmol}_{\mathrm{c}} \mathrm{dm}^{-3}$ de soma de bases (médio); 9,0\% de saturação por $\mathrm{Al}^{3+}(\mathrm{m})$ (muito baixo); $35,0 \%$ de saturação por bases (V) (baixo); $2,4 \mathrm{cmol}_{\mathrm{c}} \mathrm{dm}^{-3}$ de CTC efetiva (t) (médio); 6,2 $\mathrm{cmol}_{\mathrm{c}} \mathrm{dm}^{-3} \mathrm{de}$ CTC a pH 7 (T) (médio); 4,0 dag kg-1 de matéria orgânica (bom); 31, 29 e $40 \mathrm{dag} \mathrm{kg}^{-1}$ de areia, silte e argila, respectivamente. Pelas recomendações de Ribeiro et al. (1999), seriam necessários $400 \mathrm{~kg} \mathrm{ha}^{-1}$ do fertilizante mineral formulado NPK 04-30-10, para atender às necessidades da cultura.
O preparo do solo foi constituído por uma aração e a gradagem. A aplicação do resíduo orgânico foi feita a lanço, com posterior incorporação ao solo, seguido da abertura dos sulcos de semeadura com tração mecanizada. Antes da semeadura, sementes da cultivar BRS Favorita RR foram inoculadas com Bradyrhizobium japonicum, utilizando-se inoculante turfoso na proporção de 1.200 .000 bactérias por semente. A semeadura foi realizada em 27 de novembro de 2008 e o desbaste foi realizado 15 dias após emergência das plântulas, mantendo-se 15 plantas por metro.

Por ocasião da colheita, estádio $\mathrm{R}_{8}$ (FEHR et al., 1971), foram avaliadas as seguintes características: número de legumes por planta e número de grãos por legume (amostrados em 10 plantas das fileiras úteis), massa de 100 grãos, rendimento de grãos em $\mathrm{kg} \mathrm{ha}^{-1}$ (após conversão para $13 \%$ de umidade), altura da planta e altura de inserção do primeiro legume (tomadas aleatoriamente, em $\mathrm{cm}$, de 10 plantas das fileiras úteis) e índice de acamamento (avaliado segundo BERNARD; CHAMBERLAIN; LAWRENCE, 1965: nota 1 todas plantas eretas, 2 algumas plantas inclinadas ou ligeiramente acamadas, 3 todas as plantas moderadamente inclinadas ou $25-50 \%$ 
acamadas, 4 todas as plantas severamente inclinadas ou $50-80 \%$ acamadas e 5 mais de $80 \%$ acamadas). Após a colheita ainda foram realizadas amostragens de solo (profundidade 0,00-0,20 cm) nas subparcelas que não receberam fertilizante mineral, com intuito de verificar a influência do resíduo orgânico sobre parâmetros de fertilidade do solo ( $\mathrm{P}, \mathrm{K}, \mathrm{Ca}^{2+}, \mathrm{Mg}^{2+}, \mathrm{S}, \mathrm{Zn}, \mathrm{Fe}, \mathrm{Mn}, \mathrm{Cu}$, $\mathrm{B}, \mathrm{Al}^{3+}, \mathrm{H}+\mathrm{Al}$, P-rem, SB, t, T, m, V, MO e pH).

Os dados foram submetidos à análise de variância (GOMES, 2000) com auxílio do software Sisvar ${ }^{\circledR}$ (FERREIRA, 2008), a 1; 5 e 10\% de probabilidade pelo teste F. Quando pertinente, foi realizada análise de regressão polinomial com a escolha de modelos matemáticos com maior valor de coeficiente de determinação, significativos ao nível de $5 \%$. Os dados de índice de acamamento foram previamente transformados em $(\mathrm{x}+1)^{1 / 2}$.

\section{Resultados e discussão}

A análise de variância (TAB. 2) revelou que as doses de cama de frango alteraram significativamente, todas as características, exceto o número de grãos por legume.
Por sua vez, a produtividade, altura de planta, altura de inserção do primeiro legume e número de legumes por planta foram significativamente influenciadas pelas doses do fertilizante mineral. A única interação significativa foi relacionada à altura de planta, indicando dependência entre doses de cama de frango e do fertilizante mineral.

$\mathrm{O}$ número de legumes por planta aumentou linearmente em função das doses do resíduo orgânico e do fertilizante mineral. Em relação à cama de frango, a cada megagrama adicionada por hectare, o número médio de legumes por planta foi acrescido em aproximadamente 2 unidades, no primeiro ano após aplicação, neste tipo de solo (FIG. 1a), alcançando, com a utilização de $9 \mathrm{Mg} \mathrm{ha}^{-1}$, 48 legumes por planta. Com relação à adubação mineral, na sua ausência, observou-se 34 legumes por planta, ao passo que com a utilização de $400 \mathrm{~kg} \mathrm{ha}^{-1}$ do fertilizante NPK esse valor chegou a 45 legumes por planta (FIG. 1b). Esses dados mostram que esse componente de produção da soja responde mais ao aporte de nutrientes que número de grãos por legume, que não foi influenciado significativamente por nenhum fator, e o componente massa de 100 grãos, somente afetado significativamente pela cama de frango (TAB. 2), o que corrobora com Ritchie et al. (1997).

Tabela 2 - Resumo da análise de variância para número de legumes por planta (Leg/planta), número de grãos por legume (Grãos/leg.), massa de 100 grãos (M. 100 grãos), produtividade, altura de planta, altura de inserção do primeiro legume (Altura $1^{\circ}$ Leg.) e índice de acamamento (I. A.), Itutinga, MG, 2010

\begin{tabular}{lccccc}
\hline \multirow{2}{*}{ Fonte de variação } & \multirow{2}{*}{ GL } & \multicolumn{4}{c}{ Quadrados médios } \\
\cline { 3 - 6 } & 2 & Leg/planta & Grãos/leg. & M. 100 grãos & Produtividade \\
\hline Bloco & 3 & $850,44^{* * *}$ & 0,02 & 7,70 & 5133669,94 \\
Cama Frango (CF) & 6 & 76,81 & 0,01 & $7,59^{* *}$ & $19158419,81^{* * *}$ \\
Erro 1 & 4 & $276,09^{* * *}$ & 0,02 & 1,32 & 1102151,64 \\
Adubação Mineral (AM) & 12 & 53,55 & 0,02 & 0,12 & $1685475,97^{* * *}$ \\
CF x AM & 32 & 43,37 & 0,02 & 0,23 & 141968,36 \\
Erro 2 & & 22,13 & 6,31 & 7,23 & 148712,91 \\
\hline C V 1 (\%) & & 16,63 & 5,56 & 3,06 & 28,13 \\
C V 2 (\%) & GL & Altura Planta & Altura $1^{\circ}$ Leg. & 10,33 \\
\hline & 2 & 2,09 & & $59,88^{* * *}$ & I. A. \\
\hline Bloco & 3 & $1595,15^{* * *}$ & & $35,05^{* * *}$ & 0,02 \\
Cama Frango (CF) & 6 & 26,47 & & 0,90 & $0,76^{* * *}$ \\
Erro 1 & 4 & $101,72^{* * *}$ & & $20,61^{* *}$ & 0,05 \\
Adubação Mineral (AM) & 12 & $56,23^{* * *}$ & & 11,76 & 0,03 \\
CF x AM & 32 & 18,11 & & 6,18 & 0,01 \\
Erro 2 & & 6,46 & & 3,66 & 0,02 \\
\hline C V 1 (\%) & & 5,34 & 9,58 & 7,65 \\
C V 2 (\%) & & & & 7,88 \\
\hline
\end{tabular}

**Significativo ao nível de $5 \%$, pelo teste $\mathrm{F}(\mathrm{p}<0,05)$ ****ignificativo ao nível de $1 \%$, pelo teste $\mathrm{F}(\mathrm{p}<0,01)$. 

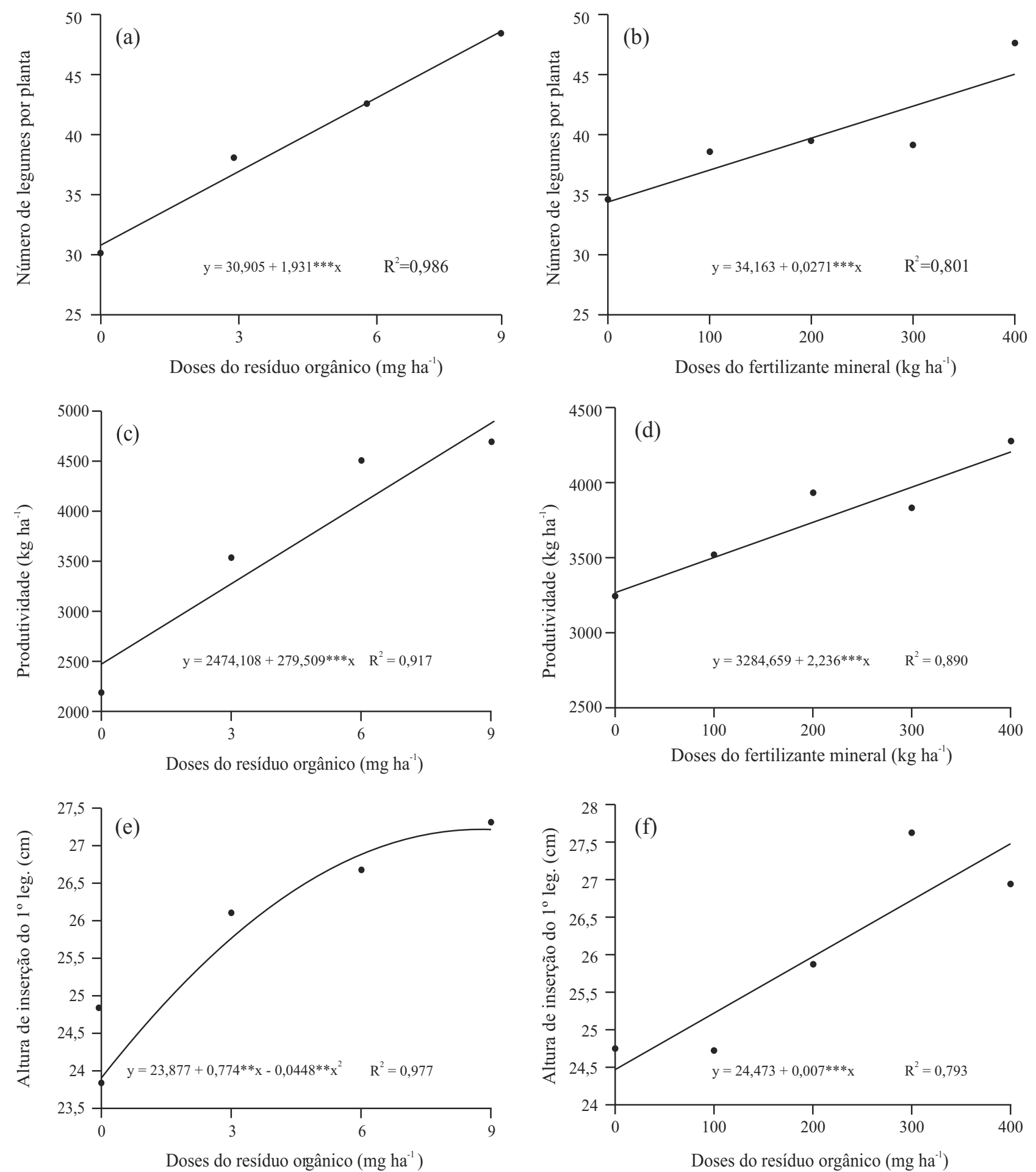

Figura 1 - Equação de regressão para produtividade $\left(\mathrm{kg} \mathrm{ha}^{-1}\right)$, altura de inserção do primeiro legume e o número de legumes por planta em função das doses do resíduo orgânico cama de frango e do fertilizante mineral, Itutinga, MG. ${ }^{* * *}$, ** significativo ao nível de 1 e $5 \%$ de significância pelo teste $\mathrm{F}$, respectivamente

Houve efeito linear das doses do resíduo orgânico e do fertilizante mineral sobre a produtividade da soja (FIG. 1c e
FIG. 1d). Nota-se que sem a utilização da cama de frango, a produtividade estimada de grãos foi de $2.474 \mathrm{~kg} \mathrm{ha}^{-1}$, ao passo 
que com a utilização de $9 \mathrm{Mg} \mathrm{ha}^{-1}$ essa produtividade foi de $4.990 \mathrm{~kg} \mathrm{ha}^{-1}$ (dobrando a produção), com acréscimo médio de $279,5 \mathrm{~kg} \mathrm{ha}^{-1}$ de grãos a cada megagrama de cama de frango adicionada por hectare (FIG. 1c).

Considerando o custo da cama de frango disponível na região (R\$ 90,00 por megagrama) e da saca de $60 \mathrm{~kg}$ de soja (R\$ 40,00), preços cotados em janeiro de 2010 junto às empresas compradoras locais, obtem-se um lucro adicional de $\mathrm{R} \$ 96,33$ por megagrama de cama de frango aplicada por hectare, sem considerar o custo do serviço de aplicação, que é variável conforme a região. Esses resultados indicam que o uso da cama de frango pode ser economicamente viável na produção de soja, dependendo da disponibilidade, dose e preço na região, mesmo porque Ribeiro et al. (2009) e Ghosh et al. (2009) ressaltam que as vantagens físicas, químicas e biológicas no solo não se limitam ao ano de aplicação do resíduo. Por outro lado, é importante atentar quanto ao desequilíbrio de nutrientes na constituição dos resíduos orgânicos, em comparação às necessidades das culturas (WESTERMAN; BICUDO, 2005), então se torna interessante a associação com fertilizante mineral, para que, a utilização contínua de resíduo orgânico não proporcione um desequilíbrio de nutrientes no sistema solo planta.

A amplitude da variação na produtividade obtida com as doses do fertilizante mineral foi menor em detrimento à observada com as doses do resíduo orgânico (FIG. 1c e FIG. 1d). Em relação à adubação mineral, na sua ausência a produtividade foi de $3.285 \mathrm{~kg} \mathrm{ha}^{-1} \mathrm{e}$ com $400 \mathrm{~kg} \mathrm{ha}^{-1}$ esse valor foi de $4.179 \mathrm{~kg} \mathrm{ha}^{-1}$, equivalente a aumento de $27 \%$ (FIG. 1d). Esses resultados indicam

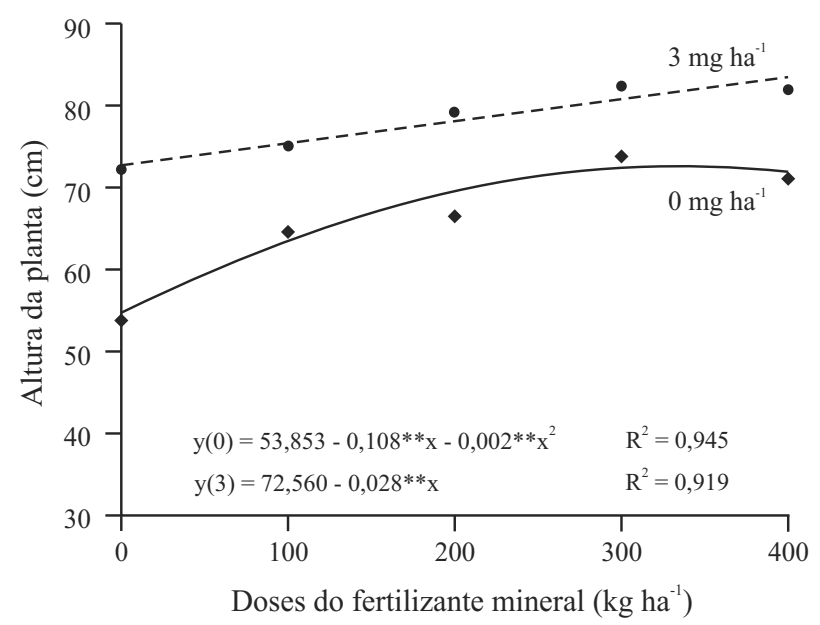

Figura 2 - Equação de regressão, desdobramentos das doses do fertilizante mineral no resíduo orgânico cama de frango para altura de planta $(\mathrm{cm})$, Itutinga, MG. ${ }^{* *}$ significativo ao nível de $5 \%$ pelo teste $\mathrm{F}$ que aplicação de altas doses de fertilizantes minerais em solos com baixa e média capacidade de troca de cátions pode não elevar proporcionalmente o rendimento. Uma das maneiras de melhorar a sustentabilidade e a eficiência agronômica dos fertilizantes minerais é a utilização conjunta com resíduos orgânicos (BHATTACHARYYA et al., 2008; LIU et al., 2009). Essa melhoria na eficiência agronômica pode ser percebida no desdobramento da interação doses de cama de frango $\mathrm{x}$ doses de fertilizante mineral para altura de planta (FIG. 2).

A altura de inserção do primeiro legume é característica importante, pois de acordo com Marcos Filho (1986), a partir de $10-12 \mathrm{~cm}$ (ideal $15 \mathrm{~cm}$ ) pode-se minimizar as perdas na colheita. Para as doses de resíduo orgânico o efeito foi quadrático (FIG. 1e), com altura do primeiro legume mínima de $23,9 \mathrm{~cm}$ e máxima de 27,2 $\mathrm{cm}$, esta obtida com a dose de $8,64 \mathrm{Mg} \mathrm{ha}^{-1}$. Com as doses do fertilizante mineral o efeito foi linear (FIG. 1f), com o menor valor em $24,5 \mathrm{~cm}$ e o maior em $27,5 \mathrm{~cm}$ com a utilização de $400 \mathrm{~kg} \mathrm{ha}^{-1}$. As variações foram de pequena magnitude, visto que se trabalhou com apenas uma cultivar, valores que se apresentaram dentro de padrões adequados para colheita mecanizada.

A interação doses de cama de frango $\mathrm{x}$ doses do fertilizante mineral foi significativa para altura de planta, sendo que os efeitos das doses do fertilizante mineral foram significativos nas doses 0 e $3 \mathrm{Mg} \mathrm{ha}^{-1}$ (FIG. 2). Na ausência da utilização da cama de frango o efeito foi quadrático, com a altura máxima, $72 \mathrm{~cm}$, alcançada com $337 \mathrm{~kg} \mathrm{ha}^{-1}$ do fertilizante mineral NPK. A partir desse ponto, a altura das plantas foi decrescendo, evidenciando que neste tipo de solo o aporte de nutrientes através de altas doses de fertilizante mineral pode não ser eficiente, visto que as perdas de nutrientes são grandes. Uma das maneiras de otimizar o uso dos fertilizantes minerais é a utilização associada à aplicação de resíduos orgânicos (BHATTACHARYYA et al., 2008; LIU et al., 2009), como a cama de frango. Observa-se que com a utilização de $3 \mathrm{Mg} \mathrm{ha}^{-1}$ desse resíduo, o efeito do fertilizante mineral sobre a altura das plantas foi linear, atingindo $84 \mathrm{~cm}$ com $400 \mathrm{~kg} \mathrm{ha}^{-1}$ do formulado NPK, mostrando maior eficiência na utilização dos nutrientes, visto que o valor máximo não foi atingido neste caso (efeito linear). Uma das causas desse efeito dos resíduos orgânicos na eficiência dos fertilizantes minerais é o aumento dos radicais orgânicos no solo, que se ligam aos nutrientes, evitando que esses sejam lixiviados. Neste sentido, Hoffmann et al. (2001) observaram que o uso de estercos animais aumentou a capacidade de troca de cátions dos solos.

A massa de 100 grãos somente foi afetada pelas doses do resíduo orgânico, com efeito linear. Verificouse o menor valor (15 g) na ausência do resíduo orgânico e o maior (16,6 g) com $9 \mathrm{Mg} \mathrm{ha}^{-1}$ (FIG. 3a). O índice de acamamento também variou em função das doses do resíduo orgânico, sendo o menor acamamento obtido sem 

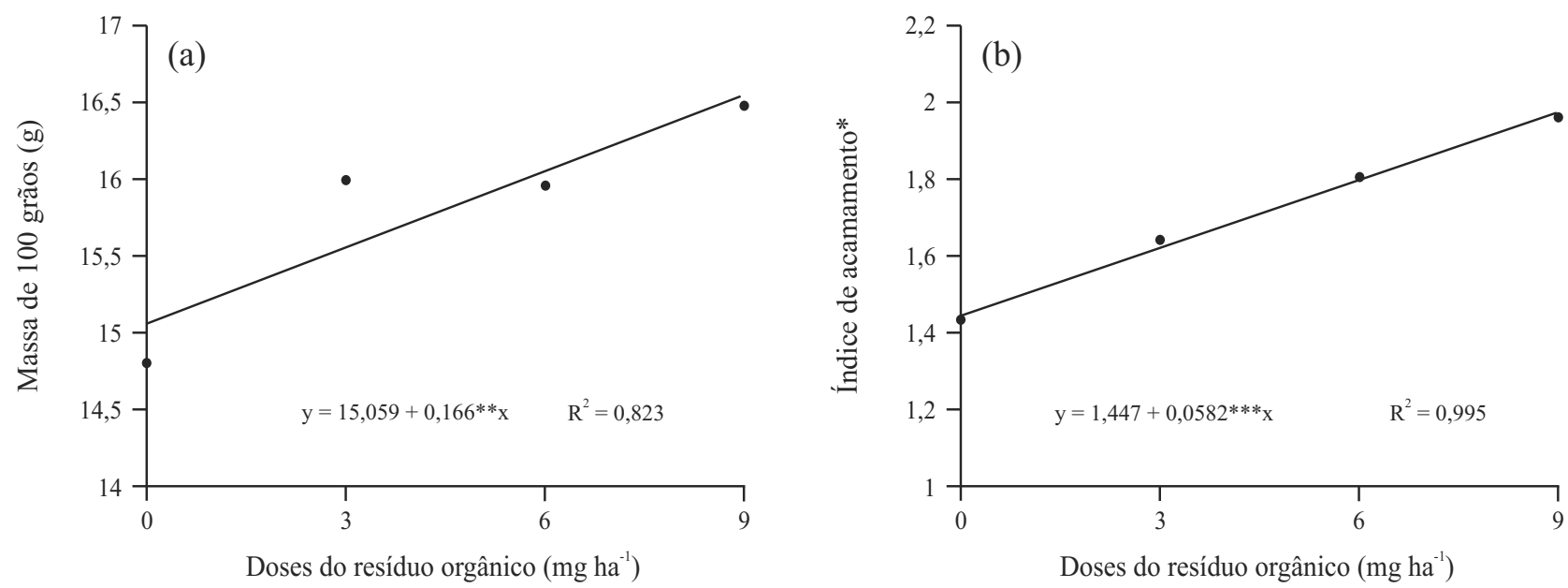

Figura 3 - Análise de regressão para massa de 100 grãos e índice de acamamento ( ${ }^{*}$ Dados transformados com $\left.(x+1)^{1 / 2}\right)$, em função das doses do resíduo orgânico cama de frango, Itutinga, MG. ${ }^{* * *, * *}$ significativo ao nível de 1 e $5 \%$ de significância pelo teste $\mathrm{F}$, respectivamente

o uso da cama de frango, índice próximo a 1 , ou seja, todas as plantas eretas, sem problema para a colheita mecanizada (FIG. 3b). À medida que se aumenta a dose do resíduo orgânico o número de plantas acamadas se eleva, até representar problema à colheita mecanizada, por favorecer as perdas. Com 3 e $6 \mathrm{Mg} \mathrm{ha}^{-1}$ os índices de acamamento (1,63 e 2,22, respectivamente), não representam problema para a colheita mecanizada. Já a dose $9 \mathrm{Mg} \mathrm{ha}^{-1}$, cujo acamamento praticamente atingiu nota 3 (todas as plantas moderadamente inclinadas ou $25-50 \%$ acamadas), favorece as perdas no momento da colheita mecanizada, restringindo assim o uso da cama de frango em doses superiores. Nessa condição, poderse-ia trabalhar com densidades de plantio menores, para amenizar esse efeito.

Após a colheita foram realizadas amostragens de solo somente nas subparcelas que não receberam fertilizante mineral. O resumo da análise de variância é apresentado na Tabela 3. A análise realizada para os atributos químicos dos solos revelou que a utilização do resíduo orgânico somente influenciou significativamente os teores de $\mathrm{K}$ e de $\mathrm{S}$ do solo (TAB. 3).

Os valores médios das características do solo em função da aplicação da cama de frango são apresentadas na Tabela 4. A matéria orgânica, ao final do cultivo, não foi afetada pela adição de cama de frango e alguns fatores provavelmente contribuíram para isto, ou seja, o plantio convencional, a incorporação desse resíduo orgânico e o clima da região, favorecem a decomposição, o que torna a elevação da matéria orgânica do solo mais difícil. Moreti et al. (2007) também verificaram que a utilização do esterco de galinha não afetou a matéria orgânica na camada de $0,00-0,20 \mathrm{~m}$. No presente trabalho, o teor de fósforo do solo no primeiro ano não foi influenciado pelo aporte da cama de frango, resultado discordante dos encontrados por Gianello e Ernani (1983) e Moreti et al. (2007) que observaram elevação do $\mathrm{P}$ extraível após aplicação de cama de frango e esterco de galinha, respectivamente.

Observou-se efeito linear das doses de cama de frango sobre o teor de $\mathrm{K}$. Na ausência da utilização de cama de frango, o teor foi de $81,97 \mathrm{mg} \mathrm{dm}^{-3}$, ao passo que com 3; 6 e $9 \mathrm{Mg} \mathrm{ha}^{-1}$ os teores foram, respectivamente, 98,$10 ; 114,23$ e $130,36 \mathrm{mg} \mathrm{dm}^{-3}$, representando acréscimos de 19,68 a 59,04\% (FIG. 4a). Esse resultado confirma os encontrados por Andreola et al. (2000) e por Moreti et al. (2007), os quais também observaram que o uso do esterco de aves proporcionou elevação do teor $\mathrm{K}$ no solo. O resíduo utilizado contém teor considerável de $\mathrm{K}, 37 \mathrm{~g} \mathrm{~kg}^{-1}$ (TAB. 1). Além disso, trata-se do primeiro cultivo após a aplicação da cama de frango, e o K, ao contrário do $\mathrm{N}$ e $\mathrm{P}$, não é muito afetado pela taxa de mineralização, ficando todo disponível às culturas, por não integrar estruturas químicas orgânicas que necessitem da mineralização microbiana (MEURER; INDA JUNIOR, 2004), a liberação de K é mais rápida em comparação ao $\mathrm{N}$ e $\mathrm{P}$ (LEITE et al., 2010). Com a utilização de $9 \mathrm{Mg} \mathrm{ha}^{-1}$ de cama de frango o teor de $\mathrm{S}$ no solo foi de $16,09 \mathrm{mg} \mathrm{dm}^{-3}$, representando acréscimo de $76,81 \%$ em relação a área onde a cama de frango não foi utilizada $\left(9,10 \mathrm{mg} \mathrm{dm}^{-3}\right)$. $\mathrm{O}$ aumento foi da ordem de $25,60 \%$ com a aplicação de $3 \mathrm{Mg} \mathrm{ha}^{-1}$ e de 51,21\% com $6 \mathrm{Mg} \mathrm{ha}^{-1}$ (FIG. 4b), indicando que a utilização de cama de frango pode favorecer o teor de $\mathrm{S}$ no solo, no 
Tabela 3 - Resumo da análise de variância para $\mathrm{P}, \mathrm{K}, \mathrm{Ca}^{2+}, \mathrm{Mg}^{2+}, \mathrm{S}, \mathrm{Zn}, \mathrm{Fe}, \mathrm{Mn}, \mathrm{Cu}, \mathrm{B}, \mathrm{Al}^{3+}, \mathrm{H}+\mathrm{Al}, \mathrm{P}-\mathrm{rem}, \mathrm{SB}, \mathrm{t}, \mathrm{T}, \mathrm{m}, \mathrm{V}, \mathrm{MO}$ e $\mathrm{pH}$, Itutinga, $\mathrm{MG}, 2010$

\begin{tabular}{|c|c|c|c|c|c|c|c|c|}
\hline \multirow{2}{*}{ Fonte de Variação } & \multirow{2}{*}{ GL } & \multicolumn{7}{|c|}{ Quadrados médios } \\
\hline & & $\mathrm{P}$ & $\mathrm{K}$ & $\mathrm{Ca}^{2+}$ & & & $\mathrm{S}$ & $\mathrm{Zn}$ \\
\hline Bloco & 2 & 1,13 & 210,58 & 0,11 & & & $33,36^{*}$ & $0,81^{*}$ \\
\hline Cama Frango & 3 & 1,11 & $1444,11 * *$ & 0,03 & & & $31,23 *$ & 0,02 \\
\hline Erro & 6 & 1,06 & 177,36 & 0,11 & & & 8,99 & 0,17 \\
\hline \multirow[t]{2}{*}{ C V (\%) } & & 43,66 & 12,54 & 26,16 & \multicolumn{2}{|c|}{25,20} & 23,81 & 26,26 \\
\hline & & $\mathrm{Fe}$ & $\mathrm{Mn}$ & $\mathrm{Cu}$ & $\mathrm{B}$ & $\mathrm{Al}^{3+}$ & P-rem & $\mathrm{H}+\mathrm{Al}$ \\
\hline Bloco & 2 & $34,83 * *$ & $9,80 * *$ & 0,17 & 0,01 & 0,00 & 13,06 & 0,39 \\
\hline Cama Frango & 3 & 5,05 & 1,49 & 0,11 & 0,01 & 0,00 & 5,21 & 0,13 \\
\hline Erro & 6 & 4,91 & 1,59 & 0,11 & 0,01 & 0,01 & 6,16 & 0,21 \\
\hline \multirow[t]{2}{*}{ C V $(\%)$} & & 7,02 & 19,26 & 22,05 & 32,98 & 55,56 & 15,02 & 11,95 \\
\hline & & SB & $(\mathrm{t})$ & $(\mathrm{T})$ & $\mathrm{m}$ & $\mathrm{V}$ & $\mathrm{MO}$ & $\mathrm{pH}$ \\
\hline Bloco & 2 & 0,19 & 0,20 & 0,32 & 12,00 & 65,64 & 0,01 & $0,03 * *$ \\
\hline Cama Frango & 3 & 0,02 & 0,01 & 0,12 & 3,64 & 8,28 & 0,05 & 0,01 \\
\hline Erro & 6 & 0,18 & 0,13 & 0,08 & 30,89 & 49,27 & 0,04 & 0,00 \\
\hline C V (\%) & & 21,77 & 17,36 & 4,79 & 71,71 & 21,13 & 7,29 & 1,24 \\
\hline
\end{tabular}

**Significativo ao nível de $5 \%$ pelo teste $\mathrm{F}(\mathrm{p}<0,05)$; *Significativo a $10 \%$ pelo teste $\mathrm{F}(\mathrm{p}<0,1)$

Tabela 4 - Resultados da análise química da amostra de solo (profundidade 0,00 - 0,20 m) na área experimental em Itutinga, MG, 2010*

\begin{tabular}{|c|c|c|c|c|}
\hline \multirow{2}{*}{ Atributos } & \multicolumn{4}{|c|}{ Cama de frango $\left(\mathrm{Mg} \mathrm{ha}^{-1}\right)$} \\
\hline & 0 & 3 & 6 & 9 \\
\hline $\mathrm{P}\left(\mathrm{mg} \mathrm{dm} \mathrm{dm}^{-3}\right)$ & 1,7 & 3,2 & 2,2 & 2,4 \\
\hline $\mathrm{K}\left(\mathrm{mg} \mathrm{dm} \mathrm{m}^{-3}\right)$ & 80,3 & 105,0 & 105,3 & 134,0 \\
\hline $\mathrm{Ca}^{2+}\left(\mathrm{cmol}_{\mathrm{c}} \mathrm{dm}^{-3}\right)$ & 1,4 & 1,3 & 1,4 & 1,2 \\
\hline $\mathrm{Mg}^{2+}\left(\mathrm{cmol}_{\mathrm{c}} \mathrm{dm}^{-3}\right)$ & 0,3 & 0,3 & 0,4 & 0,4 \\
\hline $\mathrm{S}\left(\mathrm{mg} \mathrm{dm} \mathrm{m}^{-3}\right)$ & 9,6 & 11,4 & 12,1 & 17,2 \\
\hline $\mathrm{Zn}\left(\mathrm{mg} \mathrm{dm}^{-3}\right)$ & 1,6 & 1,5 & 1,7 & 1,5 \\
\hline $\mathrm{Fe}\left(\mathrm{mg} \mathrm{dm}^{-3}\right)$ & 30,5 & 30,9 & 31,4 & 33,4 \\
\hline $\operatorname{Mn}\left(\mathrm{mg} \mathrm{dm}{ }^{-3}\right)$ & 5,9 & 6,3 & 6,4 & 7,5 \\
\hline $\mathrm{Cu}\left(\mathrm{mg} \mathrm{dm}^{-3}\right)$ & 1,8 & 1,4 & 1,4 & 1,5 \\
\hline $\mathrm{B}\left(\mathrm{mg} \mathrm{dm} \mathrm{m}^{-3}\right)$ & 0,1 & 0,2 & 0,3 & 0,2 \\
\hline $\mathrm{Al} 3+\left(\mathrm{cmol}_{\mathrm{c}} \mathrm{dm}^{-3}\right)$ & 0,1 & 0,2 & 0,1 & 0,2 \\
\hline $\mathrm{H}+\mathrm{Al}\left(\mathrm{cmol}_{\mathrm{c}} \mathrm{dm}^{-3}\right)$ & 3,8 & 3,8 & 3,7 & 4,2 \\
\hline $\mathrm{SB}\left(\mathrm{cmol}_{\mathrm{c}} \mathrm{dm}^{-3}\right)$ & 1,9 & 1,9 & 2,0 & 1,9 \\
\hline P-rem (mg L-1) & 14,7 & 16,6 & 17,6 & 17,3 \\
\hline (t) $\left(\mathrm{cmol}_{\mathrm{c}} \mathrm{dm}^{-3}\right)$ & 2,0 & 2,1 & 2,2 & 2,1 \\
\hline (T) $\left(\mathrm{cmol}_{\mathrm{c}} \mathrm{dm}^{-3}\right)$ & 5,7 & 5,6 & 5,8 & 6,1 \\
\hline $\mathrm{m}(\%)$ & 7,7 & 9,0 & 6,3 & 8,0 \\
\hline V (\%) & 33,6 & 33,4 & 35,0 & 31,0 \\
\hline MO $\left(\right.$ dag kg $\left.{ }^{-1}\right)$ & 2,8 & 2,6 & 2,8 & 2,7 \\
\hline pH em água & 5,6 & 5,5 & 5,5 & 5,5 \\
\hline
\end{tabular}



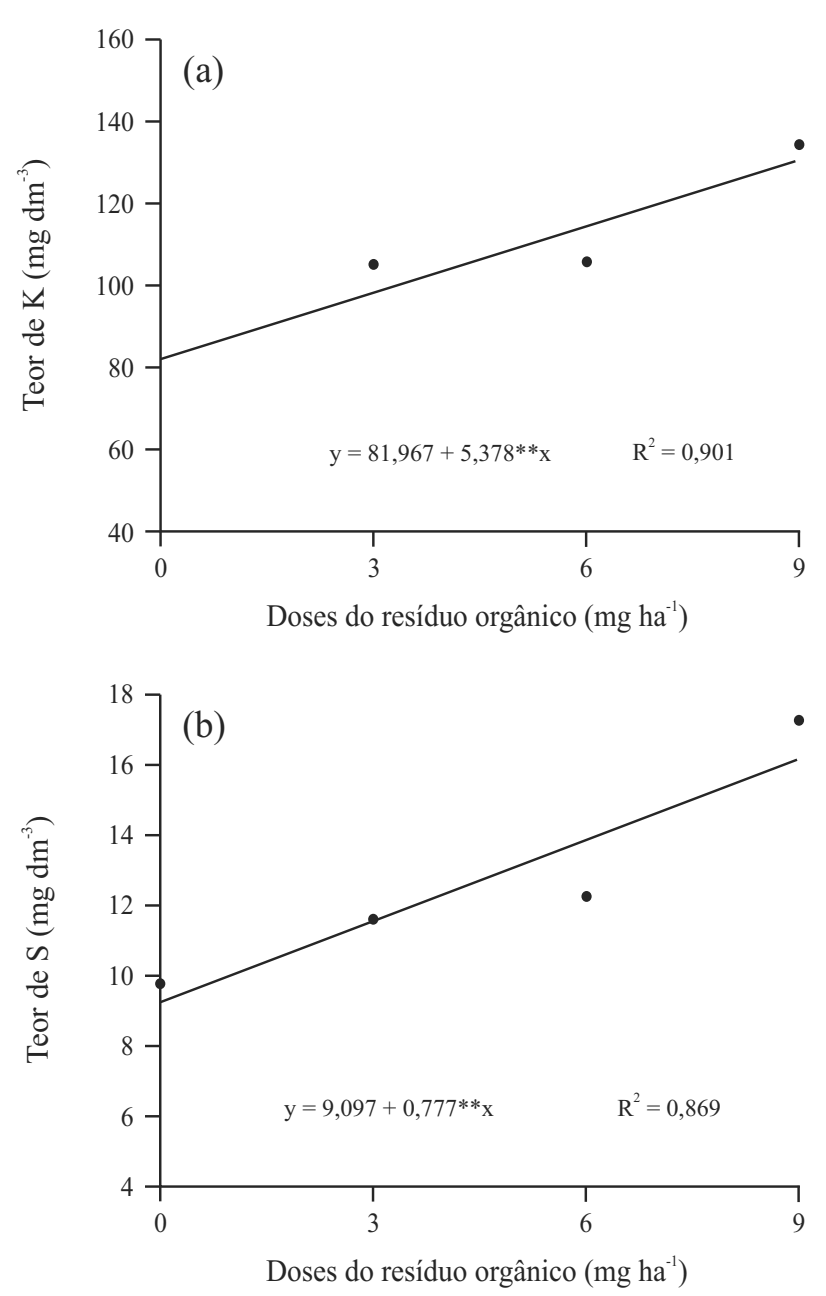

Figura 4 - Análise de regressão para teores de K e S no solo, camada $0,00-0,20 \mathrm{~m}$, em função das doses do resíduo orgânico cama de frango, Itutinga, MG. ** significativo ao nível de $5 \%$ pelo teste $\mathrm{F}$

primeiro ano de aplicação. Este resultado é interessante, visto que Rezende et al. (2009) observaram acréscimos na produtividade de soja em função da utilização desse nutriente.

\section{Conclusões}

1. A adubação com o fertilizante mineral proporciona aumento na altura de planta e de inserção do primeiro legume, número de legumes por planta e na produtividade de grãos de soja;

2. A adubação com o resíduo orgânico "cama de frango" eleva a altura de planta e de inserção do primeiro legume, massa de 100 grãos, número de legumes por planta e o rendimento de grãos de soja, porém em doses mais elevadas favorece o acamamento da plantas;

3. A utilização da cama de frango é viável em termos agronômicos e econômicos na cultura da soja;

4. A adição de cama de frango eleva os teores de K e S no solo.

\section{Agradecimentos}

À Coordenação de Aperfeiçoamento de Pessoal de Nível Superior (CAPES) pela concessão da bolsa de mestrado ao primeiro autor e à Fundação de Amparo à Pesquisa do Estado de Minas Gerais (FAPEMIG) e Conselho Nacional de Desenvolvimento Científico e Tecnológico (CNPq) pelo auxílio financeiro.

\section{Referências}

ANDREOLA, F. et al. Propriedades químicas de uma terra roxa estruturada influenciadas pela cobertura vegetal de inverno e pela adubação orgânica e mineral. Revista Brasileira de Ciência do Solo, v. 24, n. 03, p. 609-620, 2000.

BERNARD, R. L.; CHAMBERLAIN, D. W.; LAWRECE, R. $D$. (Eds.). Results of the cooperative uniform soybean tests. Washington, DC: USDA, 1965. $134 \mathrm{p}$.

BHATTACHARYYA, R. et al. Sustainability under combined application of mineral and organic fertilizers in a rainfed soybean-wheat system of the Indian Himalayas. European Journal of Agronomy, v. 28, n. 01, p. 33-46, 2008.

CASTRO, S. H.; REIS, R. P.; LIMA, A. L. R. Custos de produção da soja cultivada sob sistema de plantio direto: estudo de multicasos no oeste da Bahia. Ciência e Agrotecnologia, v. 30, n. 06, p. 1146-1153, 2006.

CORRÊA, J. C. et al. Aplicação superficial de escória, lama cal, lodos de esgoto e calcário na cultura da soja. Pesquisa Agropecuária Brasileira, v. 43, n. 09, p. 1209-1219, 2008.

COSTA, A. M. et al. Potencial de recuperação física de um latossolo vermelho, sob pastagem degradada, influenciado pela aplicação de cama de frango. Ciência e Agrotecnologia, v. 33, p. 1991-1998, 2009. Número especial.

DANTAS, A. A. A.; CARVAlHO, L. G., FERREIRA, E. Classificação e tendências climáticas em Lavras, MG. Ciência e Agrotecnologia, v. 31, n. 06, p. 1862-1866, 2007.

EMPRESA BRASILEIRA DE PESQUISA AGROPECUÁRIA (EMBRAPA). Centro Nacional de Pesquisa de Solos. Sistema brasileiro de classificação de solos. 2. ed. Rio de Janeiro, 2006. 306 p.

FEHR, W. R. et al. Stage of development descriptions for soybeans, Glycine max (L.) Merril. Crop Science, v. 11, n. 06, p. 929-931, 1971. 
FERREIRA, D. F. SISVAR: um programa para análises e ensino de estatística. Revista Symposium, v. 06, n. 02, p. 36-41, 2008.

GHOSH, P. K. et al. Assessment of nutrient competition and nutrient requirement in soybean/sorghum intercropping system. European Journal of Agronomy, v. 31, n. 01, p. 43-50, 2009.

GIANELLO, C.; ERNANI, P. R. Rendimento de matéria seca de milho e alterações na composição química do solo pela incorporação de quantidades crescentes de cama de frango, em casa de vegetação. Revista Brasileira de Ciência do Solo, v. 07, p. 285-290, 1983.

GOMES, F P. Curso de estatística experimental. 14. ed. Piracicaba: Degaspari, 2000. 477 p.

HOFFMANN, I. et al. A. Farmers management strategies to maintain soil fertility in a remote área in northwest Nigeria. Agriculture, Ecosystems \& Enviroment, v. 86, n. 03, p. 263-275, 2001.

LEITE, L. F. C. et al. Decomposição e liberação de nutrientes de resíduos vegetais depositados sobre latossolo amarelo no cerrado maranhense. Revista Ciência Agronômica, v. 41, n. 01, p. 29-35, 2010.

LEMAINSKI, J.; SILVA, J. E. Avaliação agronômica e econômica da aplicação de biossólido na produção de soja. Pesquisa Agropecuária Brasileira, v. 41, n. 10 p. 1477-1484, 2006.

LIU, M. et al. Organic amendments with reduced chemical fertilizer promote soil microbial development and nutrient availability in a subtropical paddy field: the influence of quantity, type and application time of organic amendments. Applied Soil Ecology, v. 42, n. 02, p. 166-175, 2009.

MARCOS FILHO, J. Produção de sementes de soja. Campinas: Fundação Cargill, 1986. 86 p.

MELLO, S. C.; VITTI, G. C. Desenvolvimento do tomateiro e modificações nas propriedades químicas do solo em função da aplicação de resíduos orgânicos, sob cultivo protegido. Horticultura Brasileira, v. 20, n. 02, p. 200-206, 2002.

MELO, L. C. A.; SILVA, C. A.; DIAS, B. O. Caracterização da matriz orgânica de resíduos de origens diversificadas. Revista Brasileira de Ciência do solo, v. 32, n. 01, p. 101-110, 2008.
MENEGATTI, A. L. A.; BARros, A. L. M. Análise comparativa dos custos de produção entre soja transgênica e convencional: um estudo de caso para o Estado do Mato Grosso do Sul. Revista de Economia e Sociologia Rural, v. 45, n. 01, p. 163-183, 2007.

MENEZES, J. F. S. et al. Cama de frango na agricultura: perspectivas e viabilidade técnica econômica. Rio Verde: FESURV, 2004. (Boletim Técnico, 3).

MEURER, E. J.; INDA JUNIOR, A. V. Potássio e adubos potássicos. In: BISSANI, C. A. et al. Fertilidade dos solos e manejo da adubação de culturas. Porto Alegre: Genesis, 2004. p. 139-151.

MORETI, D. et al. Atributos químicos de um latossolo vermelho sob diferentes sistemas de preparo, adubações e plantas de cobertura. Revista Brasileira de Ciência do Solo, v. 31, n. 01, p. 167-175, 2007.

REZENDE, P. M. et al. Enxofre aplicado via foliar na cultura da soja [Glycine $\max (\mathrm{L}$.) Merrill]. Ciência e Agrotecnologia, v. 33 , n. 05, p. 1255-1259, 2009.

RIBEIRO, A. C.; GUIMARÃES, P. T. G.; ALVAREZ V., V. H. (Ed.). Recomendação para o uso de corretivos e fertilizantes em Minas Gerais: $5^{\text {a }}$ aproximação. Viçosa: Comissão de Fertilidade do Solo do Estado de Minas Gerais, 1999. 359 p.

RIBEIRO, D. O. et al. Comparação de adubação química com cama de frango na cultura da soja (Glycine max) em Latossolo vermelho amarelo distrófico no sudoeste goiano. In: CONGRESSO BRASILEIRO DE SOJA, 5., 2009, Goiânia. Anais... Londrina: EMBRAPA Soja, 2009. 1 CD.

RITCHIE, S. W. et al. How a soybean plant develops. Ames: Iowa State University of Science and Technology Cooperative Extension Service, 1997. 20 p. (Special Report, 53).

SOUZA, R. F. et al. Calagem e adubação orgânica: influência na adsorção de fósforo em solos. Revista Brasileira de Ciência do solo, v. 30, n. 06, p. 975-983, 2006.

WESTERMAN, P. W.; BICUDO, J. R. Management considerations for organic waste use in agriculture. Bioresource Technology, v. 96, n. 02, p. 215-221, 2005. 